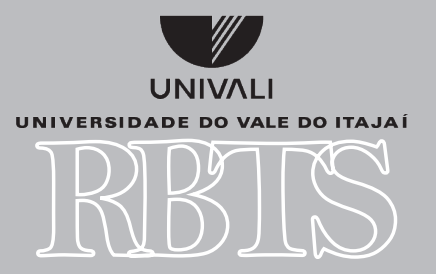

Revista Brasileira de Tecnologias Sociais
1 Graduado em Administração. Licenciado em Matemática. Mestre em Educação e Docência pela Universidade Federal de Minas Gerais (UFMG). | E-mail: hota_otavio_om@hotmail.com.

2 Graduado em Filosofia. Doutor em Educação pela Universidade Federal de Minas Gerais (UFMG). | E-mail: profpaco@ gmail.com.
Revista Brasileira de Teonologias Sociais, v.4, n.1, 2017

doi: $10.14210 /$ rbts.y4.n1.p23-36

ARTigo\$

\section{A LUTA SINDICAL COMO PROCESSO DE DEFESA DAS POLÍTICAS PÚBLICAS DE EDUCAÇÃO INFANTIL NO MUNICÍPIO DE BETIM}

\section{TRADE UNION STRUGGLE AS A PROCESS OF DEFENSE OF PUBLIC POLICIES FOR CHILDREN'S EDUCATION IN THE MUNICPALITY OF BETIM}

\author{
Otávio Henrique Ferreira da Silva ${ }^{1}$ \\ Ademilson de Sousa Soares ${ }^{2}$
}

RESUMO: O artigo é parte da dissertação de mestrado que estudou as políticas públicas de Educação Infantil no município de Betim e tem como objetivo analisar as ações do Sindicato Único dos Trabalhadores em Educação de Minas Gerais (Sind-UTE) nas políticas públicas de Educação Infantil em Betim no período correspondente a 20112016. A base metodológica para esta parte da pesquisa foi a análise de documentos sobre a Educação Infantil na cidade. Como resultado, aponta-se o lugar de destaque ocupado pelo Sind-UTE nas lutas em defesa da Educação Infantil. No entanto, fica evidenciada a necessidade de que a população betinense participe mais dessas lutas. Uma proposta promissora, nesse sentido, seria a criação de um Fórum Municipal da Educação Infantil para a construção de um projeto na cidade para a educação da primeira infância.

PALAVRAS-CHAVE: Educação Infantil; Sindicalismo; Educação pública.

ABSTRACT: The article is part of a master's dissertation that studied the public policies of Early Childhood Education in the municipality of Betim, with the aim of analyzing the actions of the Sindicato Único dos Trabalhadores em Educação de Minas Gerais (Sind-UTE) ¿Single Union of Workers in Education of Minas Gerais (SindUTE) in the public policies of Early Childhood Education in Betim, from 2011 to 2016. The methodological basis for this part of the research was the analysis of documents on Early Childhood Education in the municipality. The results demonstrate the prominent role played by the Sind-UTE in the struggles in defense of Early Childhood Education. However, there is a clear need for the population of Betim to become more actively involved in these struggles. A promising proposal, in this sense, would be the creation of a Municipal Forum of Early Childhood Education, for the construction of a project in the city for the area.

KEYWORDS: Early Childhood Education. Syndicalism. Public Education. 
UNIVALI

UNIVERSIDADE DO VALE DO ITAJAÍ

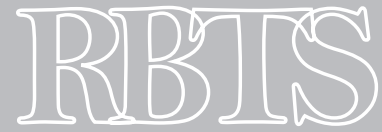

Revista Brasileira de Tecnologias Sociais 


\section{INTRODUÇÃO}

Durante o curso de Mestrado Profissional Educação e Docência na Universidade Federal de Minas Gerais, buscou-se estudar a trajetória das políticas públicas de Educação Infantil na cidade de Betim, Estado de Minas Gerais. Esta pesquisa resultou na produção da dissertação intitulada "A participação da comunidade escolar na gestão da Educação Infantil de Betim/MG" e em dois produtos da pesquisa, requisitos obrigatórios nos cursos de mestrados profissionais, que foram o livro "Educação Infantil em Betim (1958-2016)" e o "Curso para a implementação do Projeto Político Pedagógico” realizado em dois Centros Infantis Municipais (CIMs)․ As análises, as reflexões e as produções, a partir do curso de mestrado, possibilitaram reconhecer a importância que o movimento de classe tem para o alcance de conquistas históricas na Educação Infantil do município e da região metropolitana de Belo Horizonte. As primeiras lutas e reivindicações em defesa do atendimento à primeira infância como política de Estado ocorridas nas cidades de Contagem, Belo Horizonte e Betim, emergem no final da década de 1970, organizadas principalmente por mulheres no Movimento de Luta Pró-Creches (MLPC). Este movimento, mesmo não sendo uma instituição sindical, pois se preocupava não somente com as questões profissionais, mas com as instituições de Educação Infantil como um todo, foi um movimento popular que organizou a categoria de trabalhadoras(es) de creches comunitárias, e o MLPC tinha demandas como a profissionalização das pessoas que atuavam nas instituições (SILVA, 2004). No passar dos anos, principalmente a partir do século XXI, na medida em que as prefeituras foram assumindo a responsabilidade direta por parte do atendimento da Educação Infantil e realizando concursos públicos para a contratação das profissionais, os sindicatos passaram a ocupar papel de protagonista na defesa da classe de profissionais da Educação Infantil.

Ao relacionar os temas "Educação Infantil" e "Movimento Sindical”, é preciso enfatizar que o Sindicato Único dos Trabalhadores em Educação de Minas Gerais (Sind-UTE) tem ocupado lugar de destaque no Estado mineiro. Nos tempos recentes, o Sind-UTE tem realizado um movimento em busca de representar as(os) profissionais da Educação Infantil em âmbito estadual. No ano de 2012, foi realizado por esta entidade o " $1^{\circ}$ Seminário Estadual de Educação Infantil”, no qual as(os) trabalhadoras(es) da área iniciaram o processo de construção da "identidade de classe" (SIND-UTE/MG, 2012a). No mesmo ano, o sindicato divulgou também um estudo prospectivo da "Evolução das Matrículas da Educação Infantil nas Redes Públicas Municipais de Minas Gerais: contribuição à discussão das Carreiras da Educação Básica” (SIND-UTE/MG, 2012b).

O Sind-UTE, conforme aponta Oliveira (2006), nasce na nova onda de sindicalismo como uma instituição da sociedade civil e não como um braço do aparelho estatal. Inicialmente, funcionava como uma associação, e após a regulamentação dos sindicatos dos servidores públicos na Constituição de 1988, torna-se oficialmente um sindicato. Nos últimos anos, o Sind-UTE tem realizado no município de Betim uma intensa defesa de melhores condições de trabalho das profissionais da Educação Infantil, valorização das(os) trabalhadoras(es), infraestrutura física das instituições, gestão democrática para os cargos de coordenação e direção e várias outras demandas que abrangem tanto a situação laboral das profissionais quanto as políticas públicas de educação voltadas para primeira infância.

Foi observado durante a realização da pesquisa que, na medida em que as profissionais concursadas começam a chegar para trabalhar nas instituições públicas de Educação Infantil (a

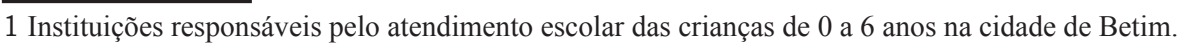


partir do mês de agosto de 2011 ), logo, buscaram organização das reivindicações da categoria junto ao Sind-UTE Subsede Betim. Durante o período analisado, a cidade de Betim foi governada por duas diferentes gestões, sendo 201 1-2012 pela prefeita Maria do Carmo Lara, filiada ao Partido dos Trabalhadores (PT) e que, historicamente, traz concepções de um governo popular com proposta de orçamento participativo e 2013-2016 pelo prefeito Carlaile Pedrosa, filiado ao Partido da Social Democracia Brasileira (PSDB) e que, historicamente, tem uma proposta governista conservadora com baixo potencial de participação popular nas tomadas de decisão.

A organização deste artigo nasce a partir dos dados levantados e resultados alcançados durante a pesquisa e tem como objetivo analisar as ações e as incidências do Sind-UTE nas políticas públicas de Educação Infantil de Betim no período correspondente a 2011-2016. A base metodológica adotada foi a análise de documentos, e-mails, arquivos disponíveis nos sites da prefeitura municipal e da câmara dos vereadores, entre outros que estão relacionados aos registros históricos da Educação Infantil na cidade. O artigo foi estruturado por esta introdução, sete seções analíticas, considerações finais e referências.

\section{CONSIDERAÇÕES SOBRE O PERFIL DAS PROFISSIONAIS DA EDUCAÇÃO INFANTIL}

Uma compreensão necessária ao adentrarmos nesse campo de estudo é entender o significado do que são as "profissionais da Educação Infantil”. De acordo com Silva (2004, p. 117), o significado dessa expressão dependerá “[ [...] fundamentalmente de quem a utiliza e dos contextos de ação nos quais são compartilhados campos semânticos que os constituem”. As instituições de Educação Infantil que atendem à camada popular contaram durante muito tempo com pessoas voluntárias (não remuneradas), que não possuíam formação específica e que recebiam distintas denominações, como pajens, babás, crecheiras e mãe crecheira. O movimento recente da busca por consolidar um perfil para os profissionais da educação, e que tem como marco a Lei de Diretrizes e Bases da Educação Nacional (LDB), representa também um esforço paulatino de militantes e pesquisadoras(es) na busca pelo reconhecimento e profissionalização das trabalhadoras da Educação Infantil (SILVA, 2004).

Por outro lado, como demonstra Ferreira (2016), o reconhecimento dos profissionais da educação na legislação não representou ainda o reconhecimento de todos os funcionários que trabalham nas instituições escolares. Esse reconhecimento fica restrito nos olhos dos governantes apenas aos docentes, o que demonstra ser uma limitação histórica, pois se pensa no desenvolvimento dos profissionais da educação, mas sem pensar em todos os profissionais envolvidos na educação das crianças, jovens e adultos. Uma das principais lutas do movimento sindical hoje é justamente assegurar constitucionalmente as "Diretrizes de Carreira dos Profissionais da Educação" para obrigar os governos a implementar políticas públicas que valorizem todos os trabalhadores da educação.

As condições de trabalho das profissionais da Educação Infantil, como retrata Ferreira e Coco (2011), muitas vezes fica à parte dos projetos políticos pedagógicos das instituições e, assim, não constrói uma avaliação crítica das políticas educacionais que estão sendo implementadas e que têm caracterizado a precarização das condições de trabalho com o aumento de contratações temporárias de docentes e com a terceirização das profissionais de cozinha, limpeza, vigilância e secretaria. Para Bufalo (2009), a precarização e a terceirização do trabalho têm se intensificado cada vez mais no serviço público e isso ocorre devido ao desdobramento das reformas educacionais

Dilva, O.H.F.; SoAres, A.S. 
promovidas pelos governos neoliberais na América Latina e no Brasil, principalmente, a partir da década de 1990 (OLIVEIRA; MELO, 2006).

Ainda há poucos estudos sobre o perfil das profissionais da Educação Infantil e suas condições de trabalho nas instituições de atendimento à primeira infância, diferente dos outros níveis educacionais, em que há uma maior concentração de pesquisas. (VIEIRA; SOUZA, 2010). Mas conforme Silva (2004), Silva (2006) e Bufalo (2009), estudar as condições de trabalho das trabalhadoras(es) da Educação Infantil e a relação destas com o movimento sindical requer também refletir sobre as relações de gênero, isto porque esta área é amplamente feminina.

As mulheres são 98,1\% dos sujeitos docentes na primeira etapa da Educação Básica, como demonstra os dados da pesquisa "Trabalho Docente na Educação Básica do Brasil”2 (VIEIRA et al., 2013). Na Educação Infantil, as jornadas de trabalho são maiores e os salários menores, sendo que $81,9 \%$ das trabalhadoras recebem renda de até três salários mínimos. Apenas 37\% das profissionais docentes da Educação Infantil são reconhecidas como professoras. Isso torna mais complexo ainda o perfil das profissionais da Educação Infantil, visto as variadas denominações com que essas trabalhadoras são tratadas. E, ainda, cerca de 52,0\% delas não possuem nenhum plano de cargos e salários (VIEIRA et al., 2013). A pesquisa mencionada traça um panorama de algumas das principais demandas das profissionais da Educação Infantil no Brasil e foi apontado: receber melhor salário, receber mais capacitação para a prática profissional, redução do número de crianças por turma, necessidade de maior apoio técnico para o exercício da prática, ter cargo de dedicação exclusiva em apenas um local de trabalho e tempo maior para atividades extraclasse.

Em outra pesquisa, realizada por Oliveira e Melo (2006, p. 122), a partir da ocorrência de atividades sindicais em um período de seis $\operatorname{anos}^{3}$ em Minas Gerais, foi constado que as principais reivindicações em geral dos trabalhadores da educação são: “[ …] de ordem Salarial, Profissional, Previdenciária, Assistencial, das Relações de Trabalho, das Condições de Trabalho, das Relações Sindicais, da Gestão Escolar e da Política Educacional mais geral”. As constatações presentes tanto em Vieira et al. (2013) quanto em Oliveira e Melo (2006) reforçam as reflexões de Bufalo (2009), quando fica constatado e reafirmado que as profissionais da Educação Infantil não reivindicam apenas salário.

\section{A CONSOLIDAÇÃO DA REDE PÚBLICA DE EDUCAÇÃO INFANTIL DE}

BETIM

No ano de 2009, durante a gestão da prefeita Maria do Carmo Lara, foi implantada uma política pelo governo municipal de ampliação da rede pública de Educação Infantil. Com isso, foram criados os cargos públicos de Educador Infantil e Auxiliar Administrativo de CIM, com a aprovação da Lei n ${ }^{\circ}$ 4.933/2009 (BETIM, 2009), tendo como justificativa que a maioria das profissionais das instituições da cidade tinham relações trabalhistas pelo regime da Consolidação das Leis Trabalhista (CLT) e que a realização de um concurso público para os cargos de educadores infantis e auxiliares administrativos era uma antiga reivindicação do MLPC e do SENALBA. ${ }^{4}$ Na

2 Esta pesquisa realizou coleta de dados no ano de 2009 e ocorreu em sete estados: Minas Gerais, Pará, Rio Grande do Norte, Goiás, Espírito Santo, Paraná e Santa Catarina.

3 A pesquisa analisa o período de 1998 a 2003.

4 O SENALBA é o Sindicato dos Empregados em Entidades Culturais, Recreativa, de Assistência Social, de Orientação e Formação Profissional, e está articulado com profissionais das creches comunitárias desde a década de 1990 na cidade (BETIM, 1996). Todavia, nos registros encontrados, sua atuação é de pouco destaque, pois foi mencionado em pouquíssimas ocasiões. 
mesma legislação também foi criado o cargo de Diretor de CIM, tendo em vista a importância de este profissional contribuir para o fortalecimento da gestão democrática na Educação Infantil (BETIM, 2010). Nos cargos de educador e diretor, a escolaridade mínima exigida era o magistério em nível médio; para os auxiliares administrativos era preciso ter nível médio completo; e na função de coordenadora pedagógica do CIM, de acordo com a legislação, essa passa a ser exercida por um educador habilitado e designado. Com relação à jornada de trabalho, o mínimo para todos os cargos ${ }^{5}$ é o cumprimento de 40 horas semanais (BETIM, 2009).

Uma questão polêmica foi a criação de cargos específicos para a Educação Infantil, sendo que, em algumas das instituições, desde a década de 1970, havia professores(as) das séries iniciais do Ensino Fundamental (PI) que trabalhavam nas creches comunitárias e tinham como obrigação o cumprimento da carga horária de 20 horas semanais. A gestão municipal fez a opção por outro cargo para o profissional do magistério, sendo o de Educador Infantil, que recebeu o mesmo nome das profissionais contratados em regime CLT pela Associação de Proteção à Maternidade, Infância e Velhice (APROMIV). Com relação ao cargo de Auxiliar Administrativo do Centro Infantil Municipal (CIM), este extraclasse foi criado para trabalhar na secretaria escolar e nos serviços de apoio à coordenação pedagógica e direção. No Ensino Fundamental, quem realiza o mesmo trabalho destes profissionais da Educação Infantil é o cargo de Técnico de Secretaria, que possui uma carga horária de 20 horas semanais. Com relação ao Diretor do CIM, o cargo também é diferente dos diretores do Ensino Fundamental, que possuem uma remuneração de acordo com o número de alunos matriculados na escola. No CIM, o salário dos diretores é único para todos, independente do número de crianças existentes na instituição. Com relação à coordenação pedagógica, no Ensino Fundamental quem realiza esse trabalho são as profissionais ocupantes do cargo efetivo de Pedagogo(a); e na Educação Infantil, para o desempenho desta função, não foi criado um cargo específico (e efetivo) e sim uma função que é assumida por designação. Apesar de haver um tratamento diferenciado para a Educação Infantil - o que é necessário devido ao fato de haver nessa etapa educacional peculiaridades no trabalho com crianças que estão no início da vida -, a diferenciação dada na criação destes novos cargos optou pela desvalorização das(os) trabalhadoras(es) ao condicioná-las(os) com salários menores e jornada de trabalho maior do que é aplicado para as profissionais que trabalham com o Ensino Fundamental na mesma rede de educação.

\section{A CONSTRUÇÃO DA IDENTIDADE DE CLASSE JUNTO AO SIND-UTE BETIM}

Em 2011 foi realizado um concurso público para toda a rede de educação municipal de Betim. A grande novidade ficou por conta deste se tornar o primeiro concurso para os profissionais da Educação Infantil da cidade. Inicialmente, estava prevista a contratação imediata de 247 educadores infantis e 18 auxiliares administrativos do CIM. As primeiras nomeações ocorreram no dia 23 de julho de 201 1, para os educadores infantis; e em 30 de julho de 2011, para os auxiliares administrativos de CIM. A partir de agosto deste mesmo ano, as(os) trabalhadoras(es) efetivos começaram a chegar para trabalhar nos centros infantis municipais, dando início ao processo de substituição das profissionais contratados via APROMIV 6 para profissionais efetivas que ingressaram por concurso público.

5 O Cargo de Diretor de CIM é de dedicação exclusiva.

6 As creches conveniadas, ao passo que foram municipalizadas, tiveram os convênios de pessoal e de custeio cancelados, sendo os profissionais recontratados diretamente pela Associação de Proteção à Maternidade à Infância e à Velhice (APROMIV), e as despesas de custeio repassadas para os CIM's por intermédio da SEMED, na medida em que estes conseguiam regularizar o funcionamento do caixa escolar próprio.

Dilva, O.H.F.; SoARes, A.S. 
O fato de haver novos profissionais com vínculo estatutário com a prefeitura municipal e também a existência de profissionais que nem sempre conheciam a trajetória de luta pela Educação Infantil do Movimento de Luta Pró-Creches de Betim, fez com que o MLPC perdesse a legitimidade de movimento organizador de classe diante das antigas instituições comunitárias que foram "municipalizadas". E também o processo de consolidação de instituições públicas com profissionais concursados, muitas vezes desconsiderou “ $[\ldots]$ até certo ponto o histórico das diversas instituições conveniadas, bem como a própria parceria MLPC/Município, através da APROMIV” (PUC/MG; CMDCA, 2012, p. 175).

Durante o segundo semestre de 2011, na medida em que os novos profissionais foram chegando aos CIMs, iniciaram-se as primeiras conversas entre o Sindicato Único dos Trabalhadores em Educação (Sind-UTE)/Subsede Betim e as(os) trabalhadoras(es) da Educação Infantil pública do município. O Sind-UTE é uma entidade social de referência em Betim, pois está presente em diversos espaços de participação, como nos Conselhos de Alimentação Escolar (CAE), no Conselho Municipal de Educação (CME), no Conselho de Controle Social do FUNDEB (COFUNDEB) e também na organização das conferências municipais de educação. Há anos (desde o início da década de 1980) está na condução das atividades sindicais dos(as) trabalhadores(as) da educação com vínculo com a Prefeitura Municipal de Betim e com a rede estadual de educação (desde 1979). A primeira pauta do diálogo do Sind-UTE com a Educação Infantil teve como temática as reivindicações salariais para 2012 e o calendário escolar do ano seguinte (SIND-UTE/BETIM, $2011 \mathrm{a}$ ).

Maior intensidade das ações ocorreu em março, com a convocação para adesão à Greve Nacional da Educação ${ }^{7}$ nos dias 14, 15 e 16, em abril, com a realização de uma assembleia geral no dia 18, quando houve paralisação total das atividades na Educação Infantil; e em maio, com a paralisação total das atividades no dia 23 de maio, quando se realizou um seminário de organização do setor e assembleia geral da Educação Infantil, culminando com a realização da primeira greve das(os) trabalhadoras(es) da Educação Infantil pública de Betim “[ [...] a partir do dia 30/05/2012, mesmo com o possível corte de ponto das educadoras” (CME/BETIM, 2012. p. 1).

De acordo com Cerqueira (2012), a pauta da campanha salarial de 2012 foi protocolada no dia 3 de janeiro. Contudo, até a data de início da greve não houve diálogo entre prefeitura e SindUTE para a discussão dos problemas enfrentados pelas(os) trabalhadoras(es) da Educação Infantil da rede pública de Betim. As principais reivindicações eram os pontos referentes às condições de trabalho, sendo que muitos dos CIMs foram "municipalizados” em prédios com condições precárias de funcionamento; a ausência de um plano de carreira para as profissionais era outra demanda; a jornada de trabalho, que além de estar sendo reivindicada a sua redução, era preciso ser adequada aos momentos de planejamento e ao horário de estudo para os(as) educadores(as); e o pagamento do Piso Salarial Profissional Nacional, que até o momento não havia sido cumprido, conforme determina a Lei Federal no 11.738/2008 (CERQUEIRA, 2012; SIND-UTE/BETIM, 2011 b).

\section{LUTAS E CONQUISTAS DURANTE O ANO DE 2013}

A partir do segundo semestre de 2012, o sindicato tem se mobilizado para garantir a participação das(os) trabalhadoras(es) dos CIM's nas atividades promovidas pelo Fórum Mineiro de Educação Infantil (FMEI), que antes contava com maior participação apenas dos gestores

7 Evento nacional realizado anualmente pela Confederação Nacional dos Trabalhadores em Educação (CNTE). No ano de 2012, a Greve Nacional teve como lema: Piso, Carreira e $10 \%$ do PIB no PNE. 
educacionais da cidade. Também, com a articulação proposta pelo Sind-UTE, outros órgãos de participação social vêm garantindo uma regular participação das profissionais da Educação Infantil, tais como o Conselho do Fundeb, Conselho Municipal de Educação e Conselho de Alimentação Escolar (CAE). A partir de 2013, as profissionais da Educação Infantil passam a ter a representação de trabalhadoras(es) da área na diretoria do Sind-UTE Betim, o que de certa forma contribui para a melhor organização dessas profissionais, visto que antes a diretoria do sindicato contava apenas com representantes dos Ensinos Fundamental e Médio. As ações do Sind-UTE Betim, já no início de 2013, buscaram a integração das atividades da Educação Infantil com as do Ensino Fundamental, diferentemente do ano de 2012, quando as ações aconteceram separadamente. Com isso, as pautas das campanhas salariais passam a englobar as demandas dos trabalhadores e das trabalhadoras das duas etapas da Educação Básica, que é de responsabilidade do município.

Em 2013, a pauta da campanha salarial contemplou 50 reivindicações dos profissionais da educação. Nas reivindicações apresentadas para a Educação Infantil, apesar de ser usado o termoo "trabalhadores", há um tratamento nas demandas com um foco maior para as(os) educadoras(es) infantis, isso em virtude da participação massiva das(os) educadoras(es) dos CIMs como representantes das(os) trabalhadoras(es) da Educação Infantil. ${ }^{8}$ Os auxiliares administrativos dos CIMs pouco contribuíram na organização da categoria durante a primeira campanha salarial em 2012, pois estavam muito dispersos dos movimentos. A partir da campanha salarial de 2013, inicia-se um processo de organização dos auxiliares administrativos nas atividades sindicais. Dali em diante passa-se a contar com a representação mais constante dos profissionais técnicos dos CIMs. ${ }^{9}$ Após a realização de paralisações, assembleias e outras atividades sindicais, as(os) trabalhadoras(es) firmaram acordos ${ }^{10}$ com a SEMED para serem cumpridos durante o ano. Em contrapartida, foi garantida a reposição dos dias paralisados. Para a Educação Infantil, foi conquistado pela primeira vez o pagamento do Piso Salarial Nacional ${ }^{11}$ aos(às) educadores(as) infantis; a unificação do calendário escolar, que a partir de 2014 passa a ser único para toda rede pública de educação, com a regulamentação das férias durante o mês de julho; e a realização da consulta popular para os cargos de diretor de CIM que, a partir de 2013, passaram a ser escolhidos democraticamente pelas comunidades escolares, substituindo as indicações que até então ficavam a cargo dos Poderes Executivo e Legislativo (SIND-UTE/BETIM, 2014).

\section{LUTAS E CONQUISTAS DURANTE O ANO DE 2014}

Em 2014, uma nova pauta de reivindicações foi construída. Com a intensificação da participação das(os) trabalhadoras(es) da Educação Infantil e do Ensino Fundamental, a pauta foi ampliada, chegando a atingir 61 demandas. Dentre as reivindicações apresentadas em 2014, observa-se que há um volume significativo de demandas dos auxiliares administrativos do CIMs que não apareceram nas campanhas salariais anteriores. Esse fato ocorreu em consequência da maior participação destes na construção das pautas dos(as) trabalhadores(as) em educação. Com

$8 \mathrm{Na}$ Educação Infantil há vários segmentos de profissionais, porém os concursados são as educadores infantis e auxiliares administrativos. A partir de 2013 começam a chegar aos CIM's as atendentes de apoio pedagógico. Os demais trabalhadores são representados por outros sindicatos, no entanto o Sind-UTE, durante as campanhas salariais do período dessa gestão, tem reivindicado o fim da terceirização com a realização de concurso público.

9 No dia $1^{\circ}$ de novembro de 2013 foi realizada a primeira reunião específica entre o Sind-UTE e os auxiliares administrativos dos CIM's para tratar da organização do setor (SIND-UTE/BETIM, 2013).

10 "Termo de acordo contendo obrigação de fazer que entre si celebram, de um lado, a administração municipal de Betim e, de outro, o Sind-UTE/MG (Sindicato Único dos Trabalhadores em Educação de Minas Gerais), Subsede Betim” (BETIM, 2013).

$11 \mathrm{O}$ pagamento do Piso Salarial iniciou em agosto do referido ano. O valor vigente era de R\$1.567,00.

Dilva, O.H.F.; SoARes, A.S. 
relação às reivindicações de 2013 , a maioria das demandas anteriores foi novamente pontuada em 2014, o que demonstrou o descumprimento por parte da gestão municipal do acordo realizado com os(as) trabalhadores(as) em educação. Entre os meses de janeiro e abril de 2014, aconteceram diversas reuniões de representantes, assembleias, manifestações pelas ruas da cidade, porém diante do não cumprimento de muitas reivindicações de 2013 e da falta de interesse do governo municipal em valorizar os(as) trabalhadores(as) da educação, na assembleia ocorrida “[...] no dia 9 de abril de 2014 [...]”, foi aprovado o início da greve por tempo indeterminado a partir do dia 15 de abril (SIND-UTE/BETIM, 2014, p. 5). Pela segunda vez na história de Betim as(os) trabalhadoras(es) da Educação Infantil participavam de uma greve em defesa da classe.

A adesão ao movimento grevista, quando somada à participação da Educação Infantil e do Ensino Fundamental, alcançou números superiores a 70\% das(os) trabalhadores(as) em educação. Foram 25 dias de greve e, após intensas negociações, os profissionais da rede pública de Betim obtiveram algumas conquistas e firmaram um novo Termo de Acordo com a gestão Carlaile Pedrosa. Para a Educação Infantil, os avanços aconteceram na inclusão destas profissionais no Plano de Cargos, Carreira e Vencimentos e juntamente à reativação deste plano; aceitação dos certificados de curso superior em área livre para progressão na carreira dos auxiliares administrativos; reajuste de $7 \%$ para os auxiliares administrativos e para o restante do funcionalismo público; mais nomeações de auxiliares administrativos aprovados no concurso de 2011 ; elevação do salário dos diretores de CIM; pagamento de gratificação para os tesoureiros da Educação Infantil no valor de $15 \%$ do salário; aumento na gratificação recebida pelos coordenadores pedagógicos de 20\% para 30\%; mudança de nomenclatura do Educador Infantil para Professor da Educação Infantil; pagamento de gratificação de regência de $20 \%$ para os(as) professores(as) da Educação Infantil; pagamento do Piso Salarial Nacional de $2014^{12}$ para os(as) professores(as) da Educação Infantil; e a implementação da jornada de estudo do(a) professor(a) da Educação Infantil, em cumprimento da Lei $n^{\circ}$ 11.738/2008 (SIND-UTE/BETIM, 2014). Várias outras reivindicações que beneficiaram as duas etapas da Educação Básica do município foram firmadas neste termo de acordo, dentre elas: a realização de concurso público para os cargos vagos e o fim da terceirização com a realização de concurso público para os setores de cozinha e limpeza das instituições educacionais. Porém, assim como ocorreu em 2013, muitos pontos acordados entre gestão municipal e trabalhadores(as) não foram cumpridos no restante do ano de 2014.

\section{LUTAS DURANTE O ANO DE 2015}

Em 2015, a pauta dos(as) trabalhadores(as) da Rede Municipal de Educação de Betim abrangeu questões sobre os direitos trabalhistas e direitos sociais para o povo ter uma cidade digna para viver. Por isso, foram pautadas questões, como: a falta de estrutura das escolas e CIMs; a falta de investimentos em educação; a defesa de uma educação de qualidade; o repúdio contra a retirada de direitos; o pagamento do Piso Salarial; a manutenção da previdência municipal sem modificações; o repúdio contra os baixos salários; os problemas da violência na cidade; o não atendimento das reivindicações de 2013 e 2014; o repúdio contra as propostas de reajuste zero; a defesa da educação e saúde; a defesa do serviço público e da cidade; o congelamento da carreira; o não pagamento dos passivos de progressões; a defesa da gestão democrática; o repúdio contra a política de choque de gestão implementada pelo governo municipal (SIND-UTE/BETIM, 2015 a).

12 O pagamento do Piso Salarial ocorreu a partir do pagamento do mês de maio de 2014. 
Foram diversas as mobilizações. Praticamente em quase todos os meses do ano aconteceram atividades sindicais. Até no último dia letivo de 2015, a exemplo do que havia ocorrido em 2014, ocorreram tentativas de cortes nos direitos dos servidores da educação. Pela terceira vez, as profissionais da Educação Infantil de Betim entraram em greve junto com os demais trabalhadores(as) da Rede Municipal de Educação. E para o Sind-UTE, a "[ [...] greve, aprovada em assembleia no dia 23 de abril e que iniciará no dia 28, não é só por valorização e defesa da nossa previdência. É, também, uma greve por respeito e em defesa de nossa dignidade!”. (SIND-UTE BETIM, 2015b, p. 1). O período de greve durou 20 dias, e durante esse tempo aconteceram algumas mudanças que provocaram retrocessos na política de Educação Infantil da cidade. Conforme foi debatido nas plenárias do Conselho Municipal de Educação de Betim e está registrado nas atas dos dias 11 e 18 de maio de 2015, a Secretaria Municipal de Educação anunciou para os diretores dos CIMs que seriam realizadas modificações na estrutura do atendimento da Educação Infantil, substituindo professores(as) da Educação Infantil por atendentes de apoio pedagógico nas turmas de creches.

As turmas de Creche I e Creche II que atendiam até 12 crianças passaram a contar com um(a) professor (a) e uma atendente de apoio pedagógico; 16 e 18 crianças passaram a contar com um(a) professor(a) e duas atendentes de apoio pedagógico; e com 24 crianças passaram a contar com um(a) professor(a)e três atendentes de apoio pedagógico. As turmas de Creche III que têm 20 crianças passaram a contar com um(a) professor(a) e uma atendente de apoio pedagógico (BETIM, 2016a). Essas mudanças impostas pela SEMED representaram a diminuição dos cargos de professor da Educação Infantil e o avanço da precarização na primeira etapa da Educação Básica, visto que, antes, todas as(os) trabalhadoras(os) que atuavam nas turmas eram professoras(es) com a formação mínima prevista pela LDB. ${ }^{13}$ Agora, o atendimento das crianças é realizado pelos atendentes de apoio pedagógico que não possuem como requisito obrigatório a escolaridade mínima estabelecida na lei para o exercício da docência, além de também receberem salários menores que os pagos aos(às) professores(as). Tal postura adotada pela gestão municipal contrariou a recomendação que o Conselho Estadual de Educação emitiu para a SEMED, quando a esta solicitou esclarecimentos sobre a legalidade da situação que pretendia adotar.

Dessa forma, os ajudantes, por não serem professores, não se enquadram nessa excepcionalidade, ou seja, não podem ser autorizados e, consequentemente, não podem atuar em sala de aula, pois a tarefa de educar e cuidar exige formação específica, como bem define o Parecer CNE/CEB n 20/2009, que trata das Diretrizes Curriculares Nacionais para a Educação Infantil [...]. (CEE/MG, 2014, p. 1).

Neste cenário de retrocessos e de cortes de direitos, os(as) trabalhadores(as) da educação de Betim conseguiram reverter poucas, mas impactantes políticas do choque de gestão, como a tentativa de calote na previdência. ${ }^{14}$ Porém, não foi apresentada pelo governo municipal nenhuma proposta de aumento salarial ou de valorização do funcionalismo. Mesmo assim, a greve foi suspensa com a assinatura do Termo de Acordo.

$\overline{13}$ "Art. 62. A formação de docentes para atuar na educação básica far-se-á em nível superior, em curso de licenciatura, de graduação plena, em universidades e institutos superiores de educação, admitida, como formação mínima para o exercício do magistério na educação infantil e nos cinco primeiros anos do ensino fundamental, a oferecida em nível médio na modalidade normal". (BRASIL, 2014, p. 34).

14 De acordo com documento encaminhado para as instituições educacionais na tentativa de mobilização para adesão à greve, o Projeto de Lei que previa alterações na previdência traria um prejuízo de aproximadamente um bilhão e meio de reais para o Instituto de Previdência Social do Município de Betim (IPREMB). Além de outro projeto de Lei que realizaria a "Segregação de Massa" dividindo os servidores municipais em dois grupos (SIND-UTE/BETIM, 2015b).

Dilva, O.H.F.; SoARes, A.S. 


\section{LUTAS DURANTE O ANO DE 2016}

O ano de 2016 não começou diferente para as(os) trabalhadoras(es) da Educação Infantil e do Ensino Fundamental. No final de 2015, os constantes atrasos nos repasses de verbas para os caixas escolares das escolas e CIMs, ${ }^{15}$ a mudança na data de pagamento dos servidores municipais e os descumprimentos dos termos de acordo fizeram com que outras atividades sindicais ocorressem no segundo semestre de 2015, apontando, inclusive, uma assembleia com indicativo de greve para o início do ano seguinte. E em 2016, o ano letivo começou com outras medidas de precarização dos(as) trabalhadores(as), como a implantação do escalonamento de salários. A campanha salarial, não diferente do ano anterior, preocupou-se com questões dos(as) trabalhadores(as) e da população da cidade. Também houve uma preocupação com a crise política desencadeada no cenário nacional que têm representando para os(as) trabalhadores(as) uma ameaça à democracia brasileira e aos direitos trabalhistas conquistados por meio de lutas históricas realizadas no país.

Foram diversas atividades sindicais nos meses de fevereiro, março e abril. A proposta de pauta elaborada na assembleia do dia 27 de janeiro foi mais enxuta, como aconteceu em 2015 e diferente de 2013 e 2014. Em 2016, os(as) trabalhadores(as) da educação não entraram em greve, mas realizaram constantes paralisações e reduções de horário no funcionamento das escolas e dos CIM's. A partir de 2016, a organização das(os) trabalhadoras(es) da Educação Infantil teve uma estratégia diferente dos anos anteriores, pois, em vez de paralisar totalmente o atendimento dos centros infantis, as profissionais da Educação Infantil passaram a reduzir o horário de funcionamento dos CIM's, atendendo às crianças somente em um turno.

A campanha salarial de 2016 permaneceu em aberto até o meado do mês de junho. Mesmo diante das fortes retaliações do governo municipal, com ameaça e efetivação do corte de ponto dos(as) trabalhadores(as), como aconteceu com os dias de paralisação durante a Greve Nacional da Educação, ${ }^{16}$ os(as) trabalhadores(as) em educação lutaram pelos seus direitos. No entanto, a campanha salarial foi suspensa com a assinatura do Termo de Acordo pelo Sind-UTE e pela Secretaria Municipal de Educação (BETIM, 2016b).

Na campanha de 2016 não se teve nenhuma conquista para a Educação Infantil e nem para o restante da rede municipal de educação. Um acontecimento que é importante ser registrado nessa história da Educação Infantil e que demonstrou o descompromisso da gestão Carlaile Pedrosa com a educação pública, mais precisamente com a educação da infância, que é aqui considerada objeto de análise, é a falta de palavra do governo em cumprir os acordos estabelecidos. No ofício encaminhado no dia 15 de abril de 2016 pela Secretaria Municipal de Educação, foi informado para as(os) professoras(res) da Educação Infantil que seria pago o Piso Salarial de 2016 a partir do mês de maio.

A partir do dia 01 de maio de 2016, a Prefeitura Municipal de Betim, através da Secretaria Municipal da Educação, cumprindo o disposto da Lei Federal $11738 / 2008$ e tendo em vista a disponibilidade de verbas do FUNDEB para este fim, pagará o PISO NACIONAL DA EDUCAÇÃO, dos Professores da Educação Infantil, no valor de $\mathrm{R} \$ 2.135$,00 (dois mil, centro e trinta e cinco reais). (BETIM, 2016c, p. 1).

Todavia, no dia 29 de abril 2016, em um novo ofício assinado pela Secretaria de Educação, o discurso da gestão municipal é modificado, alegando que o pagamento do Piso Salarial ainda

15 Os atrasados nos repasses dos recursos para os caixas escolares foi um dos motivos que levaram o CONFUNDEB a reprovar as contas da SEMED no ano de 2015 (JORNAL O TEMPO BETIM, 2016).

16 Atividade realizada anualmente pela CNTE. Em 2016 foi realizada nos dias 15, 16 e 17 de março.

A luta sindical como processo... 
seria analisado quanto ao teor de sua legalidade devido ao fato de 2016 ser ano eleitoral: “[ ... $]$ a concessão do Piso Salarial Nacional aos professores de Educação Infantil da rede municipal de ensino se encontra em análise no setor Jurídico da Prefeitura de Betim” (BETIM, 2016d, p. 1). Mesmo após o Sind-UTE elaborar e entregar para a gestão municipal, no dia 11 de maio de 2016, um parecer sobre a legalidade do pagamento do Piso Salarial em ano eleitoral, até o presente momento as(os) trabalhadoras(es) da Educação Infantil não obtiveram nenhum retorno.

\section{CONSIDERAÇOES FINAIS}

Com a consolidação da rede pública de Educação Infantil, que representa um indicador fundamental para o atendimento público de qualidade da criança pequena, as lutas pela Educação Infantil têm sido organizadas com mais intensidade e consistência pelo Sind-UTE juntamente com as profissionais da área. Assim, é fundamental que cada vez mais nos próximos tempos seja fortalecido este sindicato. O sindicato não é a solução para todos os problemas e pensar assim seria uma ingenuidade, mas o sindicato dos(as) trabalhadores(as) é uma entidade de representação de classe que, quando unida, faz a diferença. Em Betim, o Sind-UTE tem feito a diferença na Educação Infantil e, principalmente, para não deixar a educação cair no esquecimento das gestões que pela cidade passam.

No entanto, a defesa da Educação Infantil não pode ficar a cargo somente das(os) trabalhadoras(os) que são tão desvalorizadas(os) e se encontram muitas vezes em condições de trabalho aquém do que deveria ter. As profissionais da Educação Infantil são imprescindíveis, é claro, porém as famílias e as comunidades precisam ocupar e participar mais dessas lutas e estarem também em sua organização. Essa participação precisa ser provocada e incentivada, e um possível caminho passa por discutir e implementar a gestão democrática nas instituições de Educação Infantil de Betim, começando pela discussão e pela construção de forma coletiva do projeto político pedagógico na Educação Infantil. Para tanto, tal ação depende muito da iniciativa das(os) trabalhadoras(es) que estão atuando no dia a dia da Educação Infantil.

Além da organização em nível local, outro desafio a ser superado trata-se da consolidação de um Fórum Municipal de Educação Infantil, a exemplo do que o Fórum Mineiro de Educação Infantil (FMEI) é para o Estado de Minas Gerais e os Movimentos Interfóruns de Educação Infantil do Brasil (MIEIB) são para o país. Em Betim é muito necessária a construção de um fórum específico para se tratar das questões que envolvem a Educação Infantil; a discussão de projetos para o atendimento da primeira infância na cidade; os projetos para a formação das profissionais, das mudanças legais, das mudanças de concepções na área e de muitos outros assuntos que influenciam diretamente a política pública de educação para as crianças de zero a cinco anos.

É preciso que neste fórum outras instituições públicas participem. É fundamental que gestores, trabalhadoras(es), famílias e demais interessados integrem o fórum de Educação Infantil. A ideia do fórum está atrelada à tentativa de se buscar conjuntamente soluções para os problemas do município. Os dilemas da cidade não são poucos e nem simples, pelo contrário, são muitos e complexos. Por isso, é imprescindível a criação de mais espaços e mecanismos de participação social e popular na cidade. Os fóruns têm sido uma grande referência para os debates da Educação Infantil nos entes municipais, estaduais e federal e Betim não pode ficar fora desse processo nacional de discussões.

Dilva, O.H.F.; SoARES, A.S. 
BETIM. A construção da política / a política da construção: uma experiência municipal em Educação Infantil. Betim: Prefeitura Municipal de Betim, APROMIV, 1996, p. 79.

BETIM. Comunicado SEMED 010/2016: pagamento do Piso Nacional. Betim: Prefeitura Municipal de Betim, Secretaria Municipal de Educação, 2016c, p. 1. Arquivo digitalizado.

BETIM. Comunicado SEMED 014/2016: Piso Salarial Nacional. Betim: Prefeitura Municipal de Betim, Secretaria Municipal de Educação, 2016d, p. 1. Arquivo impresso.

BETIM. Conferência de Educação do Município de Betim 2010. Texto Guia - Versão Preliminar. Betim: Prefeitura Municipal de Betim, SEMED, 2010, p. 227.

BETIM. Lei $\mathbf{n}^{\mathbf{0}}$ 4933, de 23 de dezembro de 2009: cria os cargos da Educação Infantil no município de Betim, e dá outras providências. Betim, 2009. Disponível em: <http://www.camarabetim.mg.gov.br/ norma_juridica.aspx?id=12222>. Acessado em 15 jun. 2015.

BETIM. Resolução SEMED nº 001, de 25 de janeiro de 2016: estabelece normas para a organização da Educação Infantil e do quadro de pessoal e funcional dos centros infantis municipais de Betim. Betim: Prefeitura Municipal de Betim, Secretaria Municipal de Educação, 2016a. Disponível em: <http://www. betim.mg.gov.br/arquivosorgao/orgaooficial_9_1208_1_26012016.pdf>. Acessado em: 29 mai. 2016.

BETIM. Termo de Acordo contendo obrigação de fazer que entre si celebram, de um lado, a administração municipal de Betim e, de outro, o Sind-UTE/MG (Sindicato Único dos Trabalhadores em Educação de Minas Gerais), Subsede Betim. Betim: PMB, Sind-UTE, 2013, p. 4. Arquivo impresso.

BETIM. Termo de Acordo que entre si celebra a SEMED - Secretaria Municipal de Educação de Betim e o Sind-UTE - Sindicato Único dos Trabalhadores em Educação Subsede Betim, contendo as diretrizes para a reposição de carga horária e calendário escolar em razão da Campanha Salarial Educacional 2016. Betim: PMB, SEMED, Sind-UTE, 2016b, p. 3. Arquivo impresso.

BRASIL. Câmara dos Deputados. Lei de Diretrizes e Bases da Educação Nacional. Brasília: Edições Câmara, 2014, 45 pp.

CEE/MG. Parecer no 526/2014. Belo Horizonte: Conselho Estadual de Educação de Minas Gerais, 2014, p. 3. Arquivo impresso.

CERQUEIRA, B. As condições da Educação Infantil em Betim. 28. mai. 2012. Disponível em: < http://blogdabeatrizcerqueira.blogspot.com.br/2012/05/as-condicoes-da-educacao-infantil-em.html>. Acessado em: 05 mai. 2016.

CME/BETIM. Ata da plenária de 31 de maio de 2012. Betim: Conselho Municipal de Educação de Betim, 2012. Disponível em: < http://www.betim.mg.gov.br/ARQUIVOS_ANEXO/ata_ plenaria_31052012;;20120919.pdf>. Acessado em: 03 maio 2016.

JORNAL O TEMPO BETIM. Conselho reprova contas da Secretaria de Educação. Betim, 2016. Disponível em: <http://www.otempo.com.br/o-tempo-betim/conselho-reprova-contas-da-secretaria-deeduca\%C3\%A7\%C3\%A30-1.1248825>. Acessado em: 29 mai. 2016.

OLVEIRA, D.; MELO, S. Conflito docente no Brasil e manifestações sindicais: natureza e significados. Revista Lusófana de Educação. Lisboa, n. 8, p. 117-132, 2006.

OLIVEIRA, W. de. A trajetória histórica do movimento docente de minas gerais: da UTE ao 
36 - RBTS - v.4, n.1, 2017

Sind-UTE. 2006. 411 f. Tese (Doutorado) - Universidade Federal de Minas Gerais, Programa de PósGraduação em Educação, Belo Horizonte, 2006.

PUC/MG; CMDCA. Relatório do Diagnóstico da Situação da Infância e da Adolescência do Município de Betim / MG. Betim: Pontifícia Universidade Católica de Minas Gerais; Conselho Municipal dos Direitos da Criança e do Adolescente de Betim, 2012, p. 516.

SILVA, H. L. F. da. As trabalhadoras da educação infantil e a construção de uma identidade política. 2006. 291 f. Dissertação (Mestrado) - Universidade Federal de Goiás, Programa de Pós-Graduação em Educação, Goiânia, 2006.

SILVA, I. de O. e S. Profissionais de creche no coração da cidade: a luta por reconhecimento profissional em Belo Horizonte. 2014. 297 f. Tese (Doutorado) - Universidade Federal de Minas Gerais, Programa de Pós-graduação em Educação, Belo Horizonte, 2004.

SIND-UTE/BETIM. Educação Infantil - Betim: pré-pauta de reivindicações. Betim: Sindicato Único dos Trabalhadores em Educação de Minas Gerais Subsede Betim, nov. 2011 b. Documento digital.

SIND-UTE/BETIM. Porque a Educação de Betim está em greve por tempo indeterminado? YouTube, 12 de maio de 2015. 2015a. Disponível em: <https://www.youtube.com/watch?v=XDYqlWR piY4\&spfreload=10>. Acessado em: 29 mai. 2016.

SIND-UTE/BETIM. Questão de Luta: jornal do Sindicato Único dos Trabalhadores em Educação de Minas Gerais Subsede Betim. Betim, nº 2, out. 2014.

SIND-UTE/BETIM. Sind-UTE Betim convoca: reunião de representantes da Educação Infantil. Betim: Sindicato Único dos Trabalhadores em Educação de Minas Gerais Subsede Betim, nov. 2011a. Cartaz digitalizado.

SIND-UTE/BETIM. Sind-UTE Betim informa: em função de agenda inadiável informamos a alteração da reunião com auxiliares dos CIMs. Betim: Sindicato Único dos Trabalhadores em Educação de Minas Gerais Subsede Betim, 2013, p. 1. Arquivo digital.

SIND-UTE/BETIM. Vários motivos para fazer a greve!!! Nenhum para ficar na escola sem lutar! Betim: Sindicato Único dos Trabalhadores em Educação de Minas Gerais Subsede Betim, 2015b, p. 2. Arquivo digitalizado.

SIND-UTE/MG. Boletim Sind-UTE/MG informa. Belo Horizonte, n. 72, set. 2012a.

SIND-UTE/MG. Estudo prospectivo da evolução das matrículas da Educação Infantil nas redes públicas municipais de Minas Gerais: construção à discussão das Carreiras da Educação Básica. Belo Horizonte: SIND-UTE/MG, DIEESE, 2012b, 15 pp.

VIEIRA, L. et al. Trabalho docente na educação básica no Brasil: sinopse do survey nacional referente à educação infantil. Belo Horizonte: UFMG, GESTRADO, 2013, 80 pp.

VIEIRA, L.; SOUZA, G. de. Trabalho e emprego na educação infantil no Brasil: segmentações e desigualdades. Educar em Revista. Curitiba, n. especial 1, p. 119-139, 2010.

Dilva, O.H.F.; SoARes, A.S. 